\title{
AVANÇOS RECENTES NA HIDROAMINAÇÃO DE COMPOSTOS INSATURADOS
}

\section{Luiz F. T. Novaes e Julio C. Pastre*}

Departamento de Química Orgânica, Instituto de Química, Universidade Estadual de Campinas, CP 6154, 13084-971 Campinas - SP, Brasil

Recebido em 23/12/2016; aceito em 27/03/2017; publicado na web em 16/05/2017

\begin{abstract}
RECENT ADVANCES ON HYDROAMINATION OF UNSATURATED COMPOUNDS. This review presents thermodynamics and kinetics aspects of the hydroamination reaction, recent advancements on this field for non-activated alkenes, alkynes and allenes, employing transition metal catalysis or organocatalysis, including activation by hydrogen bonding or Brønsted acids. Selected syntheses that contain a strategic hydroamination step will be discussed, and advancements on the asymmetric version will also be highlighted. The full coverage of scientific activity about hydroamination is beyond this review, therefore the examples presented are from the last ten years, except when there are historical reasons for the discussion of previous works.
\end{abstract}

Keywords: hydroamination; catalysis; total synthesis; alkaloid.

\section{INTRODUÇÃO}

Os compostos orgânicos nitrogenados são onipresentes em nossa sociedade. Aparecem na forma de biomoléculas, como proteínas, ácidos nucléicos e alcaloides, além de uma diversidade de materiais de uso diário, como polímeros, pigmentos, flavorizantes e fármacos (Figura 1).

Para a síntese dessa classe de compostos, diversas metodologias para formação de ligação $\mathrm{C}-\mathrm{N}$ foram desenvolvidas, dentre essas destacam-se $N$-alquilação, ${ }^{1,2}$ aminação redutiva com compostos carbonílicos, ${ }^{3,4} \mathrm{~N}$-acilação ${ }^{5,6}$ e acoplamento cruzado C-N. ${ }^{7,8}$ Entre os métodos modernos para construção de compostos nitrogenados complexos, a hidroaminação de compostos insaturados vem ganhando destaque e desperta interesse da comunidade científica. ${ }^{9} 10$ Essa abordagem impacta na economia de átomos do processo, o que é benéfico do ponto de vista da química verde. ${ }^{11}$

O presente texto engloba uma breve discussão sobre aspectos termodinâmicos e cinéticos da reação de hidroaminação, avanços recentes na área para reação com alcenos não ativados, alcinos e alenos, sob catálise de metais de transição ou com uso de organocatalisadores, envolvendo ativação por ligação de hidrogênio ou por ácidos de Brønsted. Sínteses selecionadas que empregam de forma estratégica o uso de reações de hidroaminação serão abordadas, e avanços no desenvolvimento de abordagens assimétricas também serão contemplados. A cobertura completa da atividade científica sobre hidroaminação está além do escopo deste texto, assim, foi dada preferência para exemplos dos últimos dez anos, exceto quando houver razões históricas para discussão de trabalhos anteriores.

\section{ASPECTOS TERMODINÂMICOS E CINÉTICOS}

A reação de hidroaminação de compostos insaturados envolve a quebra de uma ligação $\sigma \mathrm{N}-\mathrm{H}$ e uma ligação $\pi \mathrm{C}-\mathrm{C}$, com a formação das ligações $\sigma \mathrm{N}-\mathrm{C}$ e $\sigma \mathrm{C}-\mathrm{H}$. A termodinâmica da hidroaminação do estireno (5) com $\mathrm{N}$-metilanilina (6) sob catálise de paládio foi estudada por Hartwig e colaboradores ${ }^{12}$ (Esquema 1).

As constantes de equilíbrio encontradas para essa reação foram $K=1,5 \pm 0,1 \mathrm{~L} \mathrm{~mol}^{-1}$ a $80{ }^{\circ} \mathrm{C}$ e $K=0,52 \pm 0,05 \mathrm{~L} \mathrm{~mol}^{-1}$ a $110{ }^{\circ} \mathrm{C}$. Após avaliação em temperaturas intermediárias e com uso da equação<smiles>CC(C)c1c(C(=O)Nc2ccccc2)c(-c2ccccc2)c(-c2ccc(F)cc2)n1CC[C@H](O)C[C@@H](O)CC(=O)O</smiles>

Atorvastatina (1): Fármaco antilipêmico

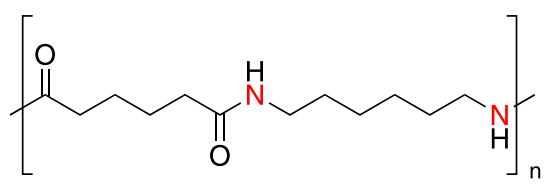

Nylon-6,6 (3): Polímero aplicado na produção de fibras<smiles>Cn1c(=O)c2c(ncn2C)n(C)c1=O</smiles>

Cafeína (2): Alcaloide estimulante do sistema nervoso central

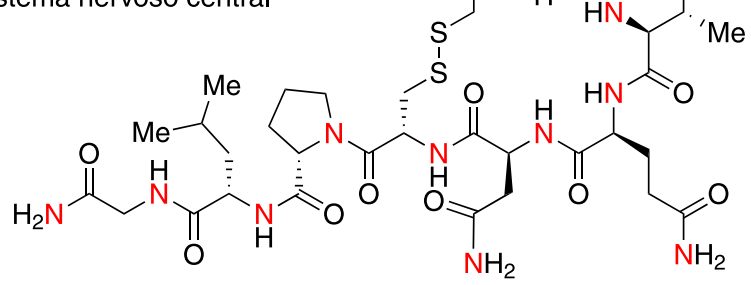

Oxitocina (4): Hormônio de origem peptídica

Figura 1. Exemplos de compostos nitrogenados 


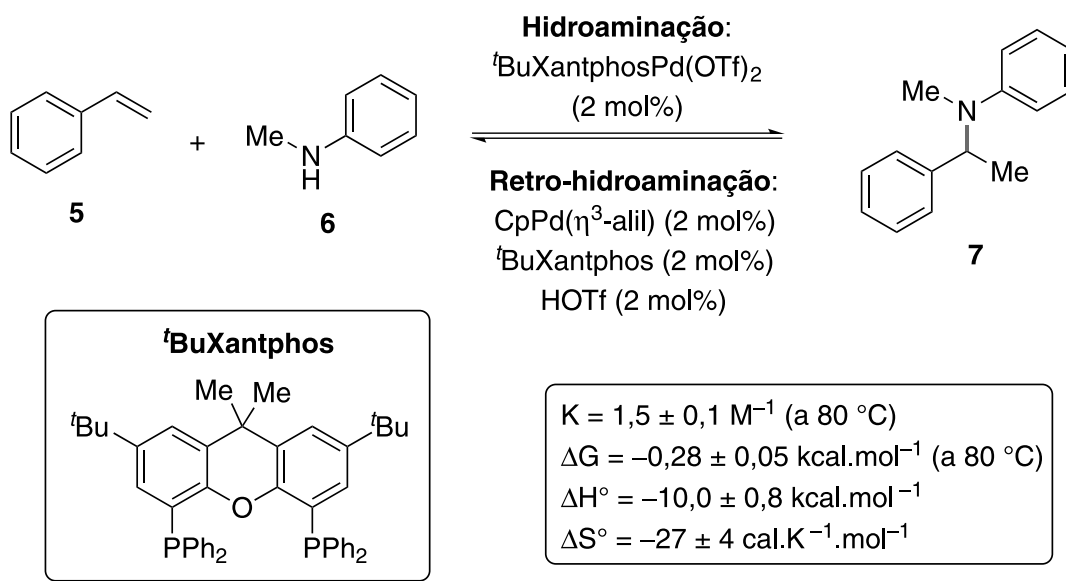

Esquema 1. Aspectos termodinâmicos da hidroaminação de estireno (5) com amina 6

de van’t Hoff (Equação 1), foram calculados $\Delta \mathrm{H}^{\circ}$ e $\Delta \mathrm{S}^{\circ}$, mostrados no Esquema 1.

$$
\ln K_{e q}=-\frac{\Delta \mathrm{H}^{\circ}}{\mathrm{RT}}+\frac{\Delta \mathrm{S}^{\circ}}{\mathrm{R}}
$$

A partir desses dados e de análise similar para outras reações de hidroaminação, foi generalizado que essa transformação usualmente é favorecida entalpicamente (exotérmica), porém esse efeito é contrabalanceado pelo termo T. $\Delta \mathrm{S}$ em intensidade similar, fazendo com que o processo seja aproximadamente ergoneutro $(\Delta \mathrm{G}=0)$.

Apesar do fator termodinâmico, a adição de aminas em ligações múltiplas C-C é cineticamente difícil, uma vez que há repulsão entre as duas espécies eletronicamente ricas. Adicionalmente, os orbitais $\sigma \mathrm{N}-\mathrm{H}$ e $\pi \mathrm{C}-\mathrm{C}$ possuem diferentes simetrias e energias. $\mathrm{O}$ uso de altas temperaturas, para cruzar a elevada energia de ativação dessa transformação, causa um deslocamento do equilíbrio em direção aos materiais de partida, em vista da entropia negativa.

A barreira energética pode ser modulada com uso de bases fortes, para gerar amidetos de metais que podem ser adicionados em ligações múltiplas C-C de modo facilitado, ou pelo uso de ácidos fortes que podem protonar ligações múltiplas $\mathrm{C}$ - $\mathrm{C}$, tornando mais fácil o ataque por um nucleófilo nitrogenado. Por fim, o grande desenvolvimento da hidroaminação ocorreu com a utilização de catálise por metais de transição atuando na ativação da ligação $\pi \mathrm{C}-\mathrm{C}$ ou ativando a espécie nitrogenada. ${ }^{9}$

\section{Hidroaminação com catalisadores à base de metais de transição}

O uso de transformações catalíticas está contemplado nos 12 princípios de química verde ${ }^{13}$ por impactarem em uma redução na geração de resíduos, quando comparados aos métodos que utilizam reagentes estequiométricos.

Nesse contexto, a utilização de complexos de metais de transição como catalisadores é atrativa, pois usualmente baixa carga catalítica é necessária para a transformação. Para as reações de hidroaminação, esses catalisadores podem atuar tanto na ativação do sistema $\pi$ dos compostos insaturados, quanto na ativação da espécie nitrogenada.

\section{Hidroaminação com amônia}

Um dos grandes desafios da reação de hidroaminação é a utilização de amônia, um reagente barato e produzido industrialmente em larga escala, mas que usualmente reage com espécies metálicas para gerar complexos ácido-base de Lewis inertes. Trabalhos de Hartwig ${ }^{14}$ e Buchwald ${ }^{15}$ sobre acoplamento de haletos de arila com amônia, via catálise de paládio, abriram caminho para estudos do seu uso em reações de hidroaminação.

Em 2008, Bertrand e colaboradore ${ }^{16}$ reportaram o uso de catalisadores de $\mathrm{Au}$ (I) com ligante do tipo (alquil)(amino)carbeno cíclico para ativação de amônia e alcinos em reações de hidroaminação (Esquema 2). Para o alcino 8, ocorreu uma reação de hidroaminação, com adição Markovnikov de $\mathrm{NH}_{3}$, e posterior tautomerização, gerando a imina 11. Para o diino 9, ocorreu inicialmente a hidroaminação de uma ligação tripla, seguida de uma segunda hidroaminação com a espécie enamina intermediária, para gerar o pirrol substituído $\mathbf{1 2}$.

Um mecanismo possível para essa transformação se baseia na proposta de Mizushima, Hayashi e Tanaka, ${ }^{17} \mathrm{em}$ que o catalisador 10 se coordena com o alcino 13, na sequência, ocorre adição de $\mathrm{NH}_{3}$ sobre a ligação tripla ativada de $\mathbf{1 4}$. Em seguida, o catalisador 10 é

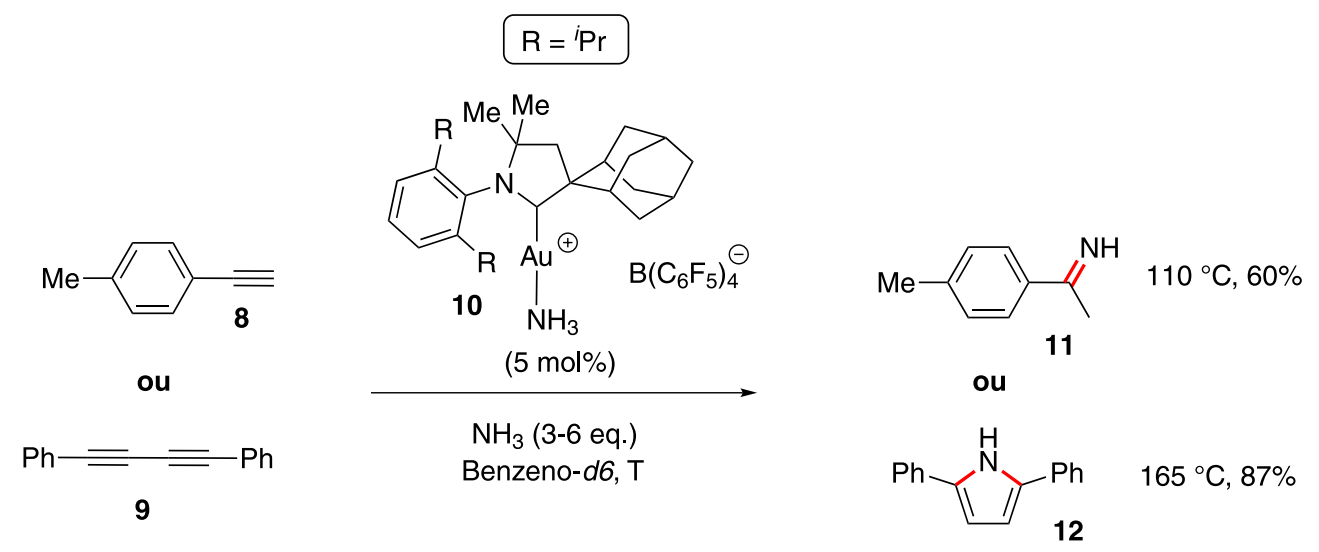

Esquema 2. Reações de hidroaminação com uso de amônia 
regenerado, liberando a enamina, que pode ser tautomerizada na imina 16 (Esquema 3).

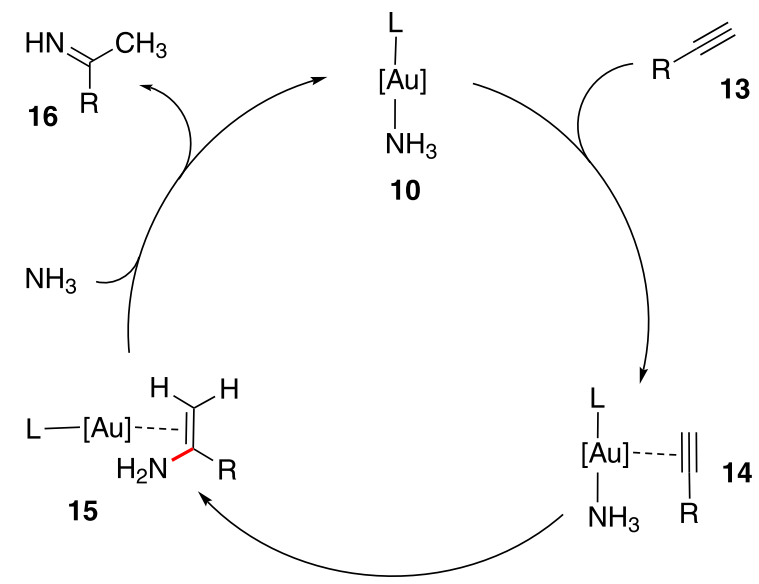

Esquema 3. Possível mecanismo para hidroaminação com $\mathrm{NH}_{3}$ e catalisador de ouro 10

Até então, apenas condições drásticas haviam sido utilizadas para a reação de hidroaminação com amônia. Um exemplo é a utilização de uma mistura de etileno e amônia em temperaturas superiores a $170{ }^{\circ} \mathrm{C}$ e pressões acima de 800 bar com sódio metálico catalítico para gerar uma mistura de etilamina, dietilamina e trietilamina. ${ }^{18}$

\section{Uso de aminas primárias: metais do grupo 4}

A hidroaminação de alcinos e alenos com aminas primárias foi extensamente estudada com catalisadores e pré-catalisadores a base de titânio e zircônio (grupo 4 da tabela periódica). ${ }^{19-21}$

O mecanismo proposto para essa transformação é mostrado a partir do titanoceno 17 e alcino 22 no Esquema 4. A espécie catalítica ativa nessa reação é o complexo metal-imido $\mathbf{2 0}$, que realiza uma cicloadição [2+2] com o alcino 22 gerando o azametalociclobuteno 23. Em seguida, esse ciclo é protonado e forma-se a espécie bis-amido $\mathbf{2 4}$, que sofre $\alpha$-eliminação da enamina, regenerando a espécie ativa metal-imido $\mathbf{2 0}$. A enamina 25 pode ser tautomerizada para a imina 26.
O pré-catalisador $\mathrm{Cp}_{2} \mathrm{TiMe}_{2}$ (17) foi empregado na síntese total do alcaloide (-)-xilopinina por Mujahidin e Doye. ${ }^{22,23}$ A partir do composto 27 foi realizada uma hidroaminação intramolecular para gerar a imina 28, após tautomerização. Uma sequência de redução assimétrica de Noyori e ciclização de Pictet-Spengler foi utilizada para a conclusão da síntese da (-)-xilopinina (Esquema 5).

Como consequência do mecanismo apresentado, a grande aplicação de catálise com os metais do grupo 4 para reações de hidroaminação se limita ao uso de aminas primárias, necessárias para formação da espécie metal-imido. Sob condições similares, a utilização de alcenos não ativados usualmente se limita a reações intramoleculares para formação de pirrolidinas e piperidinas substituídas. ${ }^{24}$

\section{Síntese de alilaminas: Catálise de paládio e ródio}

A síntese de alilaminas é particularmente interessante pela versatilidade desse bloco construtor, permitindo o uso de reações de funcionalização tanto da amina quanto da olefina. Alguns métodos desenvolvidos para a síntese desse motivo incluem substituição alílica, ${ }^{25}$ rearranjos de Overman, ${ }^{26}$ aminação $\mathrm{C}-\mathrm{H}$ alílica ${ }^{27}$ e vinilação de iminas. ${ }^{28} \mathrm{~A}$ hidroaminação aparece como uma alternativa ou método complementar, que não exige pré-instalação de um grupo de saída e pode ser realizada por catálise de metais de transição.

Yamamoto e colaboradores $^{29}$ reportaram a hidroaminação de alcinos internos do tipo 1-aril-1-propino com anilinas substituídas. O sistema catalítico composto de $\mathrm{Pd}\left(\mathrm{PPh}_{3}\right)_{4}$ e ácido benzoico inicialmente gera a espécie hidreto de paládio 32 por meio de uma adição oxidativa. $\mathrm{O}$ intermediário 32 participa de dois ciclos catalíticos, no primeiro realiza uma hidropaladação seguida de $\beta$-eliminação, para isomerizar o alcino 33 no aleno 35. No segundo ciclo, há formação do complexo paládio $\pi$-alila 36 , que pode reagir com a amina 37 , gerando a alilamina 38 e o hidreto de paládio 32 (Esquema 6).

Essa reação foi avaliada com diferentes grupos substituintes no nitrogênio da anilina. A ausência de substituinte (39), uso de grupos alquílicos (40 e 41) ou tosila (42) forneceram rendimentos iguais ou superiores a $89 \%$ (Esquema 7). No entanto, o uso de grupos terc-butoxicarbonila (Boc, 43 ) e acetila (44) não levaram à formação das respectivas alilaminas, provavelmente por tornarem o composto nitrogenado menos nucleofílico.

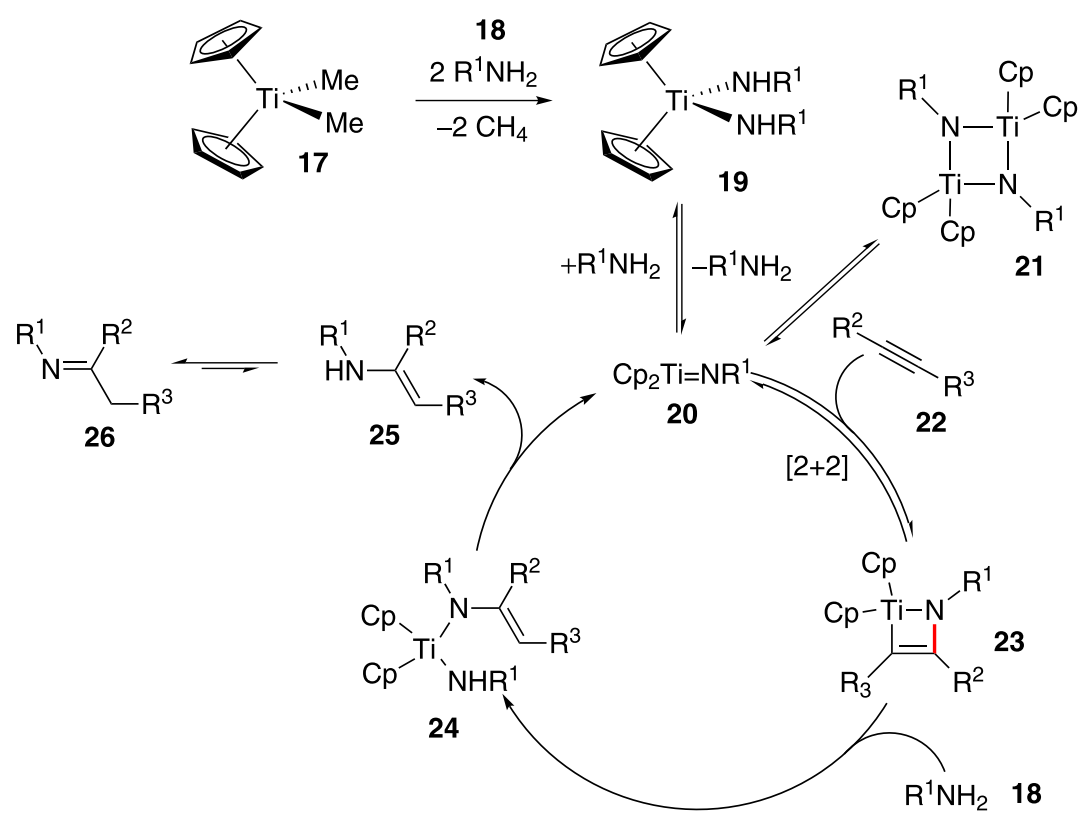

Esquema 4. Mecanismo proposto para hidroaminação catalisada por $\mathrm{Cp}_{2} \mathrm{Ti}=\mathrm{NR}^{l}$ 
<smiles>COc1ccc(C#Cc2cc(OC)c(OC)cc2CCN)cc1OC</smiles>
$\mathrm{Cp}_{2} \mathrm{TiMe}_{2}$ $(10 \mathrm{~mol} \%)$ Tolueno $110^{\circ} \mathrm{C}$ $98 \%$<smiles>COc1ccc(C[C@@H]2NCCc3cc(OC)c(OC)cc32)cc1OC</smiles><smiles>COc1cc2c(cc1OC)CN1CCc3cc(OC)c(OC)cc3[C@H]1C2</smiles>

Esquema 5. Síntese total da (-)-xilopinina via hidroaminação intramolecular

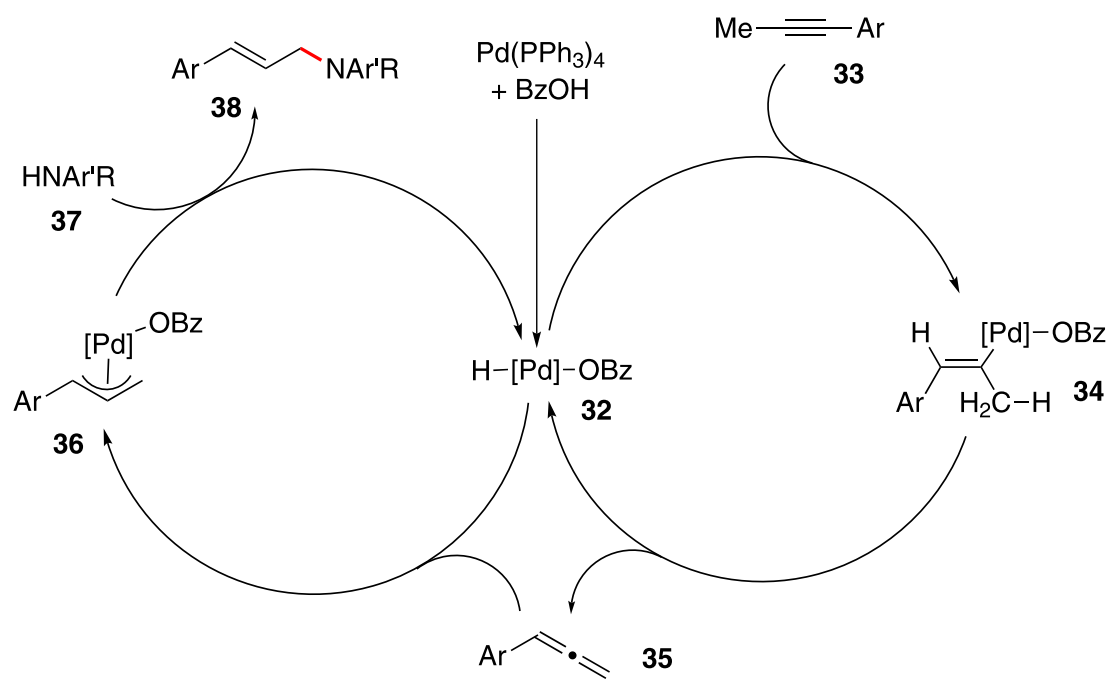

Esquema 6. Proposta mecanística da hidroaminação de 1-aril-1-propino
39, $\mathrm{R}=\mathrm{H}$
40, $\mathrm{R}=\mathrm{Me}$
41, $\mathrm{R}=\mathrm{Bn}$
42, $R=T s$
43, $R=$ Boc
44, $R=A C$<smiles>[R]Nc1ccccc1</smiles><smiles>CC#Cc1ccccc1</smiles>
$\mathrm{Pd}\left(\mathrm{PPh}_{3}\right)_{4}(5 \mathrm{~mol} \%)$
$\mathrm{PhCOOH}(10 \mathrm{~mol} \%)$
1,4-dioxano, $100^{\circ} \mathrm{C}$

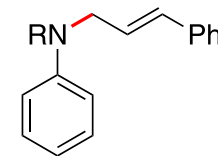
46, $\mathrm{R}=\mathrm{H}, 89 \%$
47, $\mathrm{R}=\mathrm{Me}, 93 \%$
48, $R=B n, 94 \%$
49, $R=T s, 98 \%$
50, $R=$ Boc, traços $^{a}$
(1 eq.)
(1 eq.)
$51, R=A c, 0 \%^{a}$

Esquema 7. Avaliação de escopo na formação de alilaminas. ${ }^{a}$ Recuperação completa do material de partida

A hidroaminação catalisada por paládio também foi realizada empregando alenos como material de partida, com passagem por uma espécie paládio $\pi$-alila. ${ }^{30}$

Para a síntese assimétrica de alilaminas, Breit e colaboradores ${ }^{31}$ propuseram uma hidroaminação de alenos com uma forma mascarada de amônia, a imina derivada da benzofenona, e um catalisador de $\mathrm{Rh}$ (I). Dentre os ligantes bis-fosfinas avaliados, Josiphos apresentou o melhor resultado entre rendimento e excesso enantiomérico, além disso, o uso do aditivo $p$-toluenossulfonato de piridínio (PPTS) mostrou-se essencial para obtenção de rendimentos elevados.

A aplicabilidade desse método foi demonstrada em uma reação em escala de grama do aleno 52 (Esquema 8). Na sequência, foi realizada a hidrólise da imina $\mathbf{5 4}$, gerando o cloridrato de amina $\mathbf{5 5}$ com recuperação da benzofenona (56).
O mecanismo proposto para essa transformação passa pela adição oxidativa da imina 53 e hidrometalação do aleno 52, formando o complexo ródio $\pi$-alila 57 , a eliminação redutiva leva à formação regiosseletiva do isômero ramificado $\mathbf{5 4}$ e regenera o catalisador de ródio (I).

\section{Síntese de enaminas: Catálise de rutênio com seletividade Markovnikov e anti-Markovnikov}

As enaminas são blocos de construção bastante versáteis, a alquilação desses compostos foi explorada por Stork e colaboradores, ${ }^{32} \mathrm{e}$ grande atenção foi dada à química de enaminas como um modo de ativação em organocátalise..$^{33}$

Diversos métodos para a síntese de enaminas se baseiam na condensação de um compostos carbonílicos com uma amina, empregando 


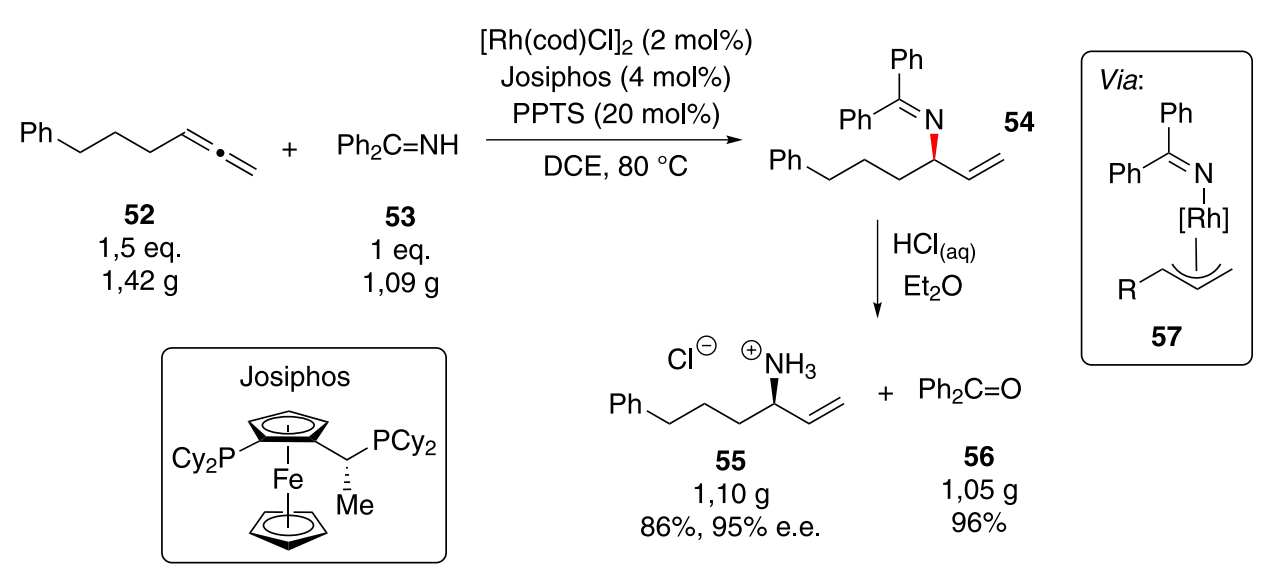

Esquema 8. Síntese assimétrica do cloridrato da alilamina 55<smiles>C#Cc1ccc(F)cc1</smiles><smiles>[CH+][N]</smiles>

6 (10 eq.)<smiles>C=C(c1ccc(F)cc1)N(C)c1ccccc1</smiles>

Esquema 9. Hidroaminação Markovnikov de alcino catalisada por rutênio

uso de ácidos ou bases. Para compostos sensíveis a essas condições, a construção dessa função também é possível via hidroaminação de alcinos com aminas secundárias.

Uchimaru relatou o primeiro uso de hidroaminação intermolecular de alcinos terminais com aminas secundárias catalisada por rutênio. ${ }^{34} \mathrm{Um}$ dos exemplos estudados foi a formação da enamina 59, através da adição Markovnikov da amina 6 sobre o alcino 58 (Esquema 9).

Essa transformação envolve a adição oxidativa da ligação $\mathrm{N}-\mathrm{H}$ da amina 6 sobre uma espécie de Ru (0), gerando o intermediário hidreto de amido-rutênio 61. Na sequência, o alcino 62 se complexa ao centro metálico e ocorre ataque do nitrogênio sobre a ligação tripla ativada, gerando a espécie 64, que após eliminação redutiva gera a enamina 65 e a espécie catalítica de Ru (0) (Esquema 10).

A catálise de rutênio também foi utilizada para realizar hidroaminação com seletividade oposta, anti-Markovnikov, utilizando alcinos terminais, aminas secundárias e o pré-catalisador 68 (Esquema 11). ${ }^{35}$

Durante o desenvolvimento dessa metodologia baseada em catálise de Ru (I), observou-se que alcinos internos não sofreram hidroaminação sob as condições mostradas no Esquema 11 e que a adição de aminas ocorre exclusivamente no carbono terminal, indicando que o mecanismo passa pela formação de uma espécie vinilideno-rutênio (70). ${ }^{36} \mathrm{Na}$ sequência, a piperidina (67) atacaria o carbono ligado diretamente no centro metálico e a protonação da ligação Ru-C levaria à enamina 69 e à espécie catalítica de rutênio.

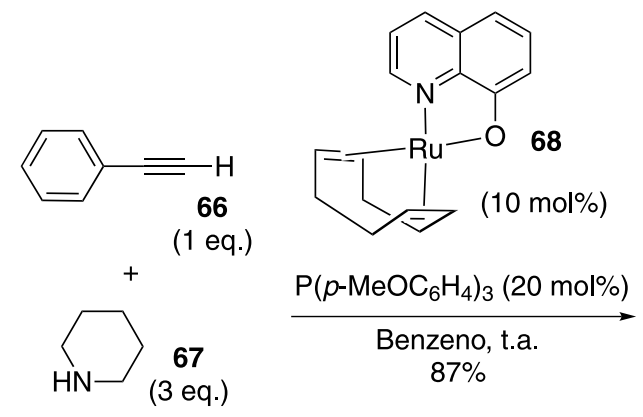

Esquema 10. Mecanismo de hidroaminação de alcinos via catálise de Ru (0)

Síntese total da (-)-quinocarcina via hidroaminação de alcino catalisada por ouro(I): Regiosseletividade controlada pelo substrato

O núcleo piperazina-tetrahidroisoquinolina aparece em uma variedade de alcaloides de arquitetura complexa, como (-)-quinocarcina, tetrazomina, lemonomicina e ecteinascidinas. ${ }^{37}$ Dentre esses, a
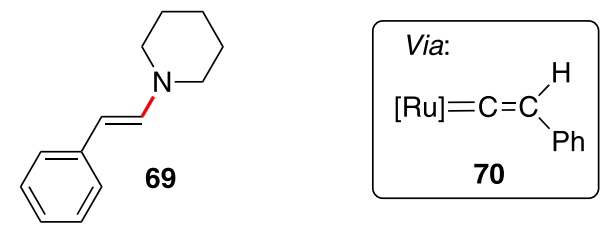

Esquema 11. Hidroaminação anti-Markovnikov de alcino catalisada por rutênio 
(-)-quinocarcina atraiu interesse de químicos sintéticos por possuir atividade antitumoral. ${ }^{38}$ Esse produto natural foi isolado em 1983 por Takahashi e Tomita. ${ }^{39}$

Em 2012, Fujii, Ohno e colaboradores ${ }^{40}$ reportaram uma estratégia convergente para a síntese total desse alcaloide natural empregando um acoplamento cruzado de Sonogashira e uma hidroaminação intramolecular catalisada por ouro (I).

Inicialmente foi realizada a síntese de quatro substratos modelos, que foram testados na etapa de hidroaminação. A reação a partir do alcino $\mathbf{7 2}$ forneceu exclusivamente a formação do anel de 5 membros 74. Assim, a modificação de uma cadeia flexível presente em $\mathbf{7 2}$ por um anel de 7 membros fundido ao sistema aromático em 75 e 78 levou a uma mistura dos produtos 6-endo e 5-exo. Finalmente, a modificação por um anel fundido de 5 membros (81) levou exclusivamente ao produto 6-endo desejado (Esquema 12). A ausência de formação do produto $\mathbf{8 3}$ provavelmente se deve à alta tensão anelar desse sistema tricíclico.

Em face desses resultados, foi realizada a síntese do composto $\mathbf{8 4},{ }^{41}$ contendo um anel de 5 membros fundido ao sistema aromático, assim a etapa de hidroaminação levou à formação exclusiva do anel de 6 membros, que foi reduzido na sequência para o composto 86 em $90 \%$ de rendimento para 2 etapas. Em seguida, interconversão de grupos funcionais e uso de protocolo relatado previamente por Allan e Stoltz ${ }^{42}$ para transformação de $\mathbf{8 9}$ em 90 levou à formação do alcaloide (-)-quinocarcina (Esquema 13).

\section{Hidroaminação fotoredox para construção de $N$-heterociclos saturados: catálise de irídio}

Um dos grandes objetivos no campo da catálise é desenvolver novos modos de ativação de pequenas moléculas, e uma abordagem que vem ganhando espaço é o uso de catálise fotoredox com luz visível. Essa estratégia se baseia no uso de complexos metálicos ou pigmentos orgânicos, que participam de um processo de transferência única de elétrons, após fotoexcitação com luz visível. ${ }^{43}$

Complexos de polipiridinas de rutênio ou irídio são usualmente empregados como catalisadores nessas transformações. Apesar desses compostos serem oxidantes e redutores pouco eficazes pela transferência única de elétron nos estados fundamentais, tornam-se bastante efetivos quando no estado excitado.

Dessa forma Knowles e colaboradores ${ }^{44}$ se basearam no mecanismo da reação de Hofmann-Löffler-Freytag e ciclização de olefina com cátion-radical nitrogenado para desenvolver um protocolo fotoredox catalítico, que utiliza luz visível para formação de $N$-heterociclos saturados. Na reação de Hofmann-Löffler-Freytag, a amina de partida é convertida em um análogo $N$-halogenado de forma estequiométrica, que é submetido à fotólise com radiação ultravioleta na presença de um ácido de Brønsted forte.

Para evitar uso de um oxidante estequiométrico, Knowles propôs o uso de um fotocatalisador para formar a espécie cátion-radical nitrogenado, que poderia então reagir com um alceno de modo intramolecular formando os $\mathrm{N}$-heterociclos de interesse. O catalisador que forneceu o melhor resultado foi $\operatorname{Ir}(\mathrm{ppy})_{2}(\mathrm{dtbbpy}) \mathrm{PF}_{6}$. O mecanismo proposto é mostrado no Esquema 14 a partir da amina 91.

Essa metodologia foi utilizada com sucesso para a preparação de diversos $N$-heterociclos substituídos: pirrolidinas (96-98), octaidroindol (99), piperidinas (100-101), morfolina (102) e piperazina (103). A regiosseletividade pode ser atribuída à formação de um radical benzílico intermediário, representado pela estrutura 93 no Esquema

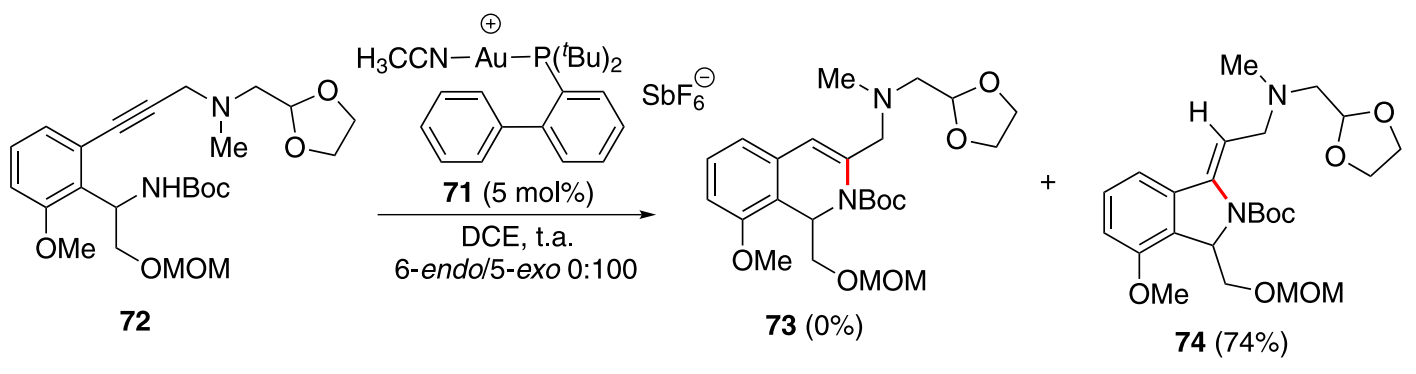<smiles>[R]C#Cc1cccc2c1C(NC(=O)OCc1ccccc1)COC(C)(C)O2</smiles>

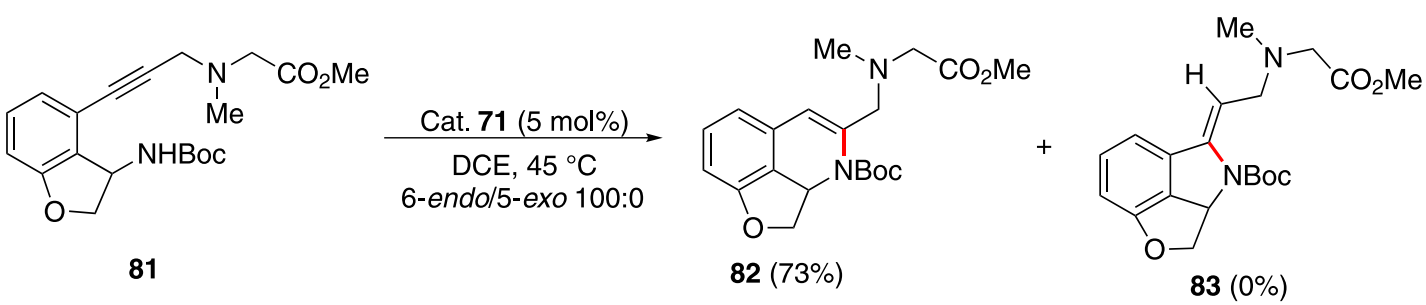

Esquema 12. Reações modelo de hidroaminação catalisadas por 71 


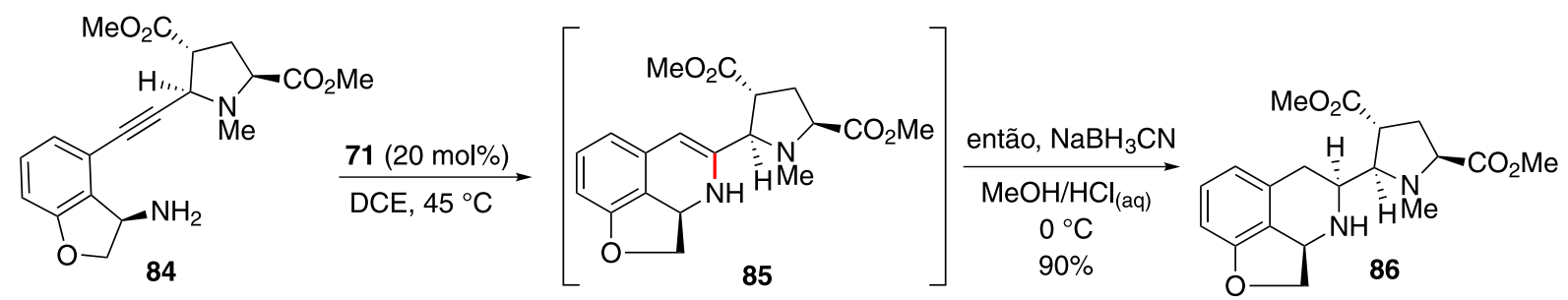

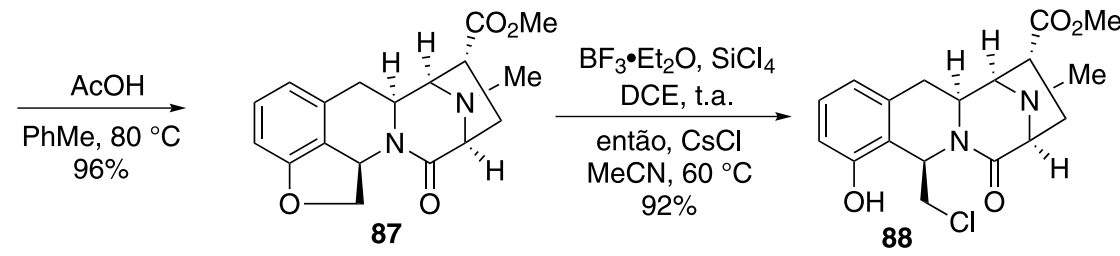

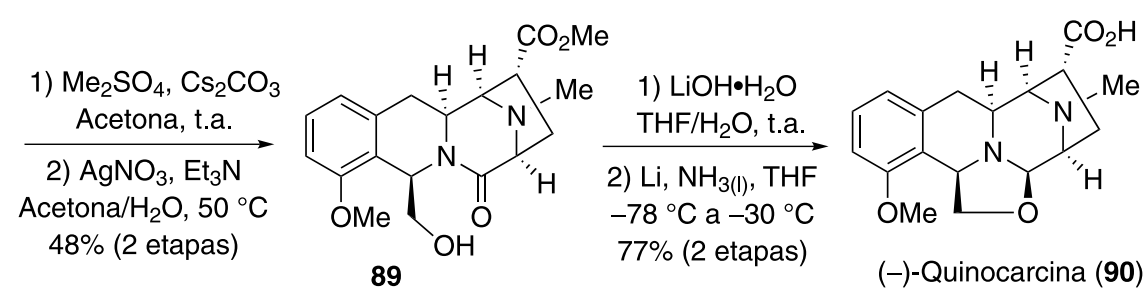

Esquema 13. Síntese da (-)-quinocarcina via hidroaminação

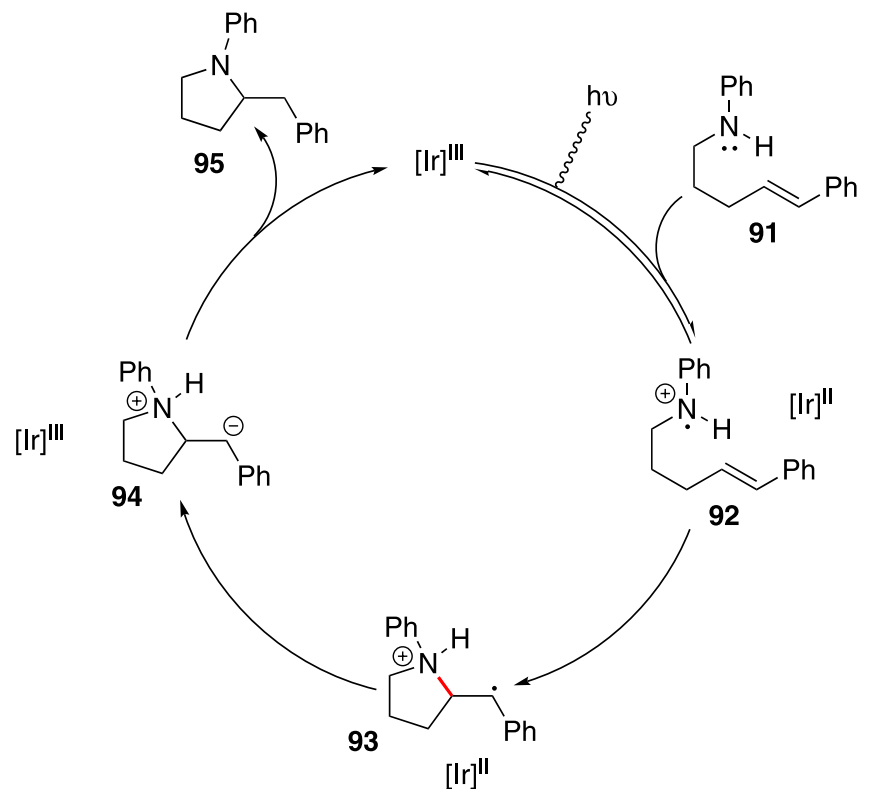

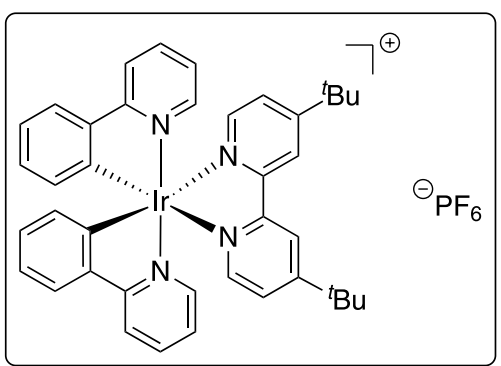

$[\mathrm{Ir}]=\operatorname{Ir}(\mathrm{ppy})_{2}(\mathrm{dtbbpy}) \mathrm{PF}_{6}$

Esquema 14. Proposta mecanística para ciclização fotocatalisada

14, tornando a ciclização exo favorecida em relação à ciclização endo. Nos casos em que mais de um centro estereogênico foi criado $(99 \mathrm{e}$ 101), baixa diastereosseletividade foi observada.

Síntese de aminas quirais com estereocentros nas posições $\alpha, \beta$, $\gamma$ ou $\delta$ : Hidroaminação formal catalisada por hidretos de cobre

A hidrofuncionalização de alcenos internos é um desafio sintético por apresentar dificuldades quanto ao controle da regio e estereosseletividade. A presença de grupos diretores nos substratos foi utilizada com sucesso para controlar a seletividade de hidrogenações, ${ }^{45,46}$ e esse conceito tem sido expandido para hidrosililação, ${ }^{47}$ hidroboração ${ }^{48} \mathrm{e}$ hidroacilação, ${ }^{49}$ em que um substituinte polar orienta a qual carbono será ligado o grupo funcional. Apesar dos avanços na reação de hidroaminação, o uso de grupos diretores para essa transformação ainda é raro.
Recentemente, Hartwig e colaboradores reportaram o uso de $\mathrm{Cu}\left(\mathrm{PPh}_{3}\right) \mathrm{H}$ catalítico, ligante $(S)$-DTBM-SEGPHOS $(\mathrm{DTBM}=$ 3,5-di-terc-butil-4-metoxi), ${ }^{50} \mathrm{HSiMe}(\mathrm{EtO})_{2}$ e uma fonte eletrofílica de grupo amino $\left(\mathrm{Bn}_{2} \mathrm{~N}-\mathrm{OBz}\right)$ para realizar hidroaminação de olefinas 1,2-dissubstituídas com a posição homoalílica funcionalizada. ${ }^{51}$ Esses resultados fornecem uma rota simples para acessar fragmentos 1,3-aminoálcoois. Foi observada correlação entre efeito indutivo do grupo OR e a seletividade entre os produtos proximal:distal, quanto mais retirador de elétrons o grupo OR, maior a seletividade observada em favor do produto proximal (Esquema 16).

Para o composto com benzoato, foi obtido um rendimento de $39 \%$, por conta da redução do grupo éster tanto do material de partida quanto do produto de hidroaminação. Assim, a adição de grupos na posição orto contribuiu para evitar a redução da carbonila do éster, 


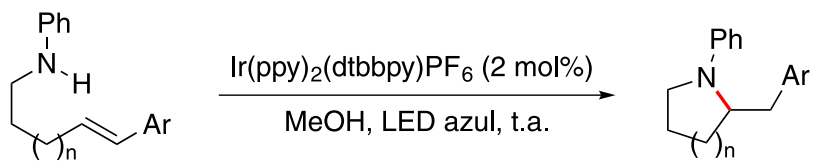<smiles>c1ccc(CC2CCCN2c2ccccc2)cc1</smiles>

$96,86 \%$<smiles>c1ccc(CC2CCCCN2c2ccccc2)cc1</smiles>

$100,66 \%$<smiles></smiles>

$\mathbf{9 7}, 76 \%$<smiles></smiles>

$98,61 \%$<smiles>Pc1ccccc1</smiles>

$99,76 \%$

r.d. 1:1<smiles>c1ccc(CC2COCCN2c2ccccc2)cc1</smiles>

$102,44 \%$

$\mathrm{Ph}$<smiles>[N-]N1CCN(c2ccccc2)C(Cc2ccccc2)C1</smiles>

$103,58 \%$ $101,64 \%$
r.d. $4,2: 1$

(Solvente: Acetona)

Esquema 15. Escopo para ciclização catalítica fotoredox

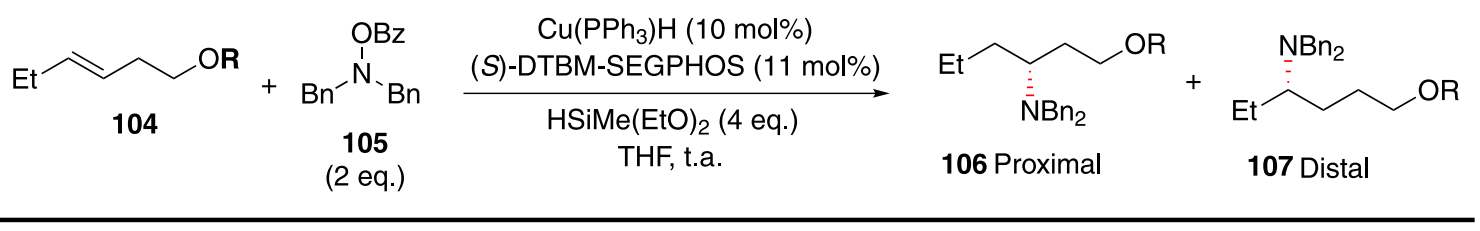

$\mathbf{R}=$<smiles>CCc1ccc(OC)cc1</smiles><smiles>CCCc1ccccc1</smiles>

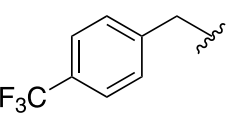<smiles>Cc1ccc(Br)cc1</smiles><smiles>CC(=O)c1ccccc1</smiles><smiles>CC(=O)c1c(Cl)cc(Cl)cc1Cl</smiles>

\section{Seletividade} Proximal:Distal $3,2: 1$

3,3:1

$3,6: 1$

$4,6: 1$

$7,1: 1$

$9,0: 1$

\begin{tabular}{cc}
\hline Rendimento & $46 \%$ \\
\hline e.e & -
\end{tabular}

$50 \%$

$52 \%$

$83 \%$

$94 \%$

\begin{tabular}{ll}
$39 \%$ & $84 \%$ \\
\hline $99 \%$ & $97 \%$
\end{tabular}

Esquema 16. Avaliação de grupos oxigenados para hidroaminação regiosseletiva

como foi observado com o grupo 2,4,6-triclorobenzoato, que forneceu um rendimento de $84 \%$.

Para distinguir se essa regiosseletividade ocorre por efeito indutivo do grupo retirador de elétrons OR ou por coordenação direta com o catalisador metálico, foi realizada a hidroaminação do composto cíclico 108. Assim, se ocorresse coordenação com o centro metálico, o produto majoritário deveria ter substituição cis, e se o efeito indutivo fosse o principal, a reação com hidreto de cobre ocorreria pela face menos impedida estericamente, fornecendo o produto trans. Ao realizar a reação, o produto foi obtido na forma majoritariamente trans (r.d.
$>95: 5$, Esquema 17),${ }^{52}$ confirmando que o efeito indutivo é o principal na regiosseletividade observada anteriormente (Esquema 16).

Um sistema similar ao mostrado foi aplicado por Buchwald e colaboradores para a síntese de aminas com estereocentro na posição $\beta$, a partir da hidroaminação de olefinas 1,1-dissubstituídas. ${ }^{53}$ Posteriormente, para formação de aminas com estereocentros remotos (posições $\gamma$ e $\delta$ ) foi utilizada uma estratégia de hidroaminação redutiva de transferência (do inglês, reductive relay hydroamination) ${ }^{54}$ Exemplos dessas abordagens estão mostrados no Esquema 18.

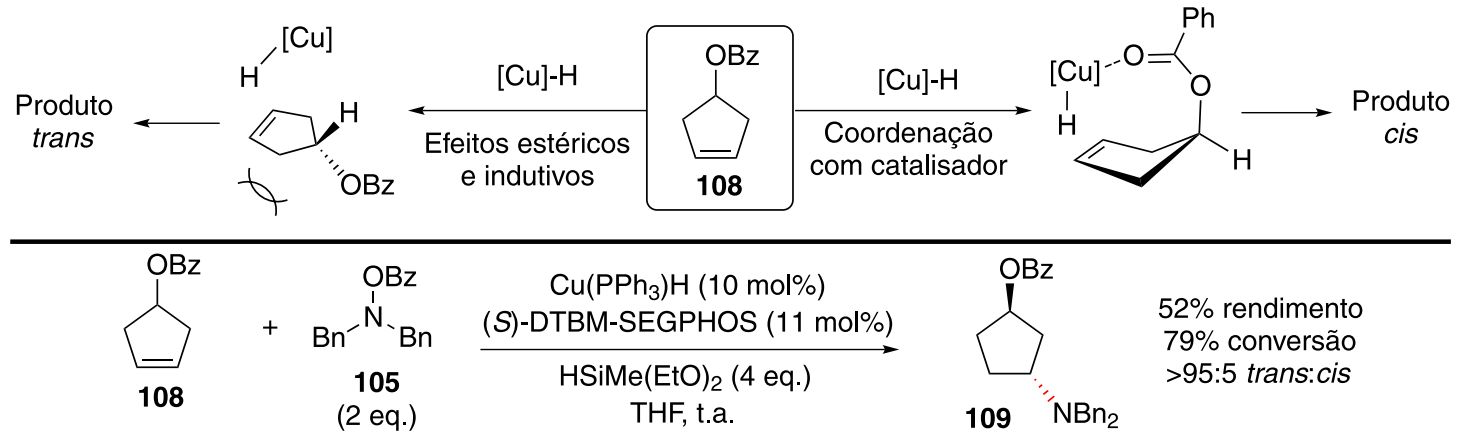

Esquema 17. Origem da seletividade da hidroaminação catalisada por hidreto de cobre 
$\beta$-estereocentro

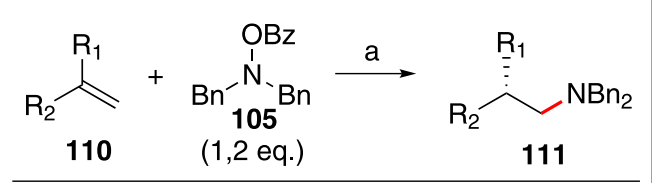<smiles></smiles>

111 a $90 \%$, $83 \%$ e.e.<smiles>CCCCNC[C@H](C)C1CCCCC1</smiles>

111b $88 \%$, 95\% e.e.<smiles>C[C@@H](Br)CNC(=O)c1ccccc1</smiles>

111c $88 \%, 60 \%$ e.e.

111d $78 \%$, 92\% e.e.

TBSO<smiles>CCCCCCCCCCCCCCCCCCCCC</smiles>

111e $92 \%$, 91\% e.e.<smiles>CCCCCC(C)C(C)(C)C(C)C(=O)OCCCC</smiles>

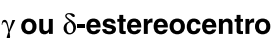

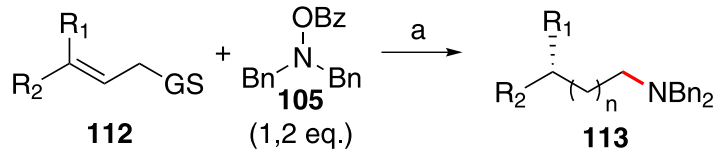

113

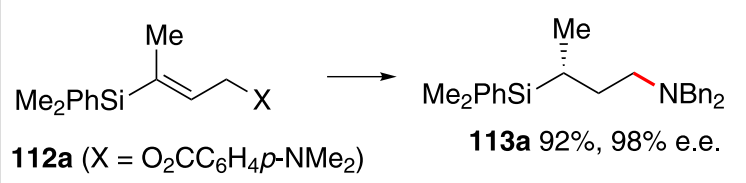

111 52\%, $90 \%$ e.e.
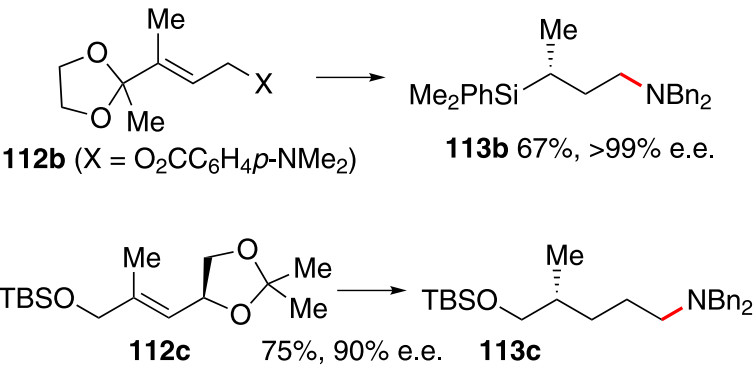

Esquema 18. Formação de estereocentros nas posições $\beta, \gamma$ e $\delta$ a partir de hidroaminação de alcenos com catálise de cobre. Condição a: $\mathrm{Cu}(\mathrm{OAc})_{2}(2 \mathrm{~mol} \%)$, (R)-DTBM-SEGPHOS (2,2 mol\%), HSiMe(EtO) 2 (2,0 - 5,0 eq.), THF. GS = grupo de saída

A regiosseletividade anti-Markovnikov observada na formação de 111a-111f foi atribuída a fatores estéricos. ${ }^{55} \mathrm{O}$ cobre se ligaria à posição menos substituída, e após etapas de adição oxidativa com o composto 105 e eliminação redutiva, a amina se instalaria no carbono anteriormente ligado ao cobre.

A proposta de mecanismo para a formação dos compostos 113a-113c passa por uma hidrocupração assimétrica de 112 seguida de eliminação do alcóxido ou carboxilato em $\beta$, formando o alceno terminal 116 (para 112c, ocorreria uma segunda sequência de hidrocupração e $\beta$-eliminação). Na próxima etapa, a olefina 116 sofreria uma hidrocupração com seletividade anti-Markovnikov, ${ }^{55}$ e após uma sequência de adição oxidativa/eliminação redutiva o fragmento dibenzilamina seria instalado. O hidrosilano é responsável pela redução dos intermediários 117 e 120, permitindo o uso catalítico do hidreto de cobre 114 (Esquema 19).

\section{Hidroaminação formal de olefinas com nitroarenos: catálise} por hidretos de ferro

Em 2014, Baran e colaboradores relataram um protocolo para formação de ligação C-C via acoplamento redutivo de olefinas. ${ }^{56,57}$ Esse método notável utilizou etanol como solvente, catalisadores de ferro (III) como $\mathrm{Fe}(\mathrm{acac})_{3}$ e $\mathrm{Fe}(\mathrm{dibm})_{3}(\mathrm{acac}=$ acetilacetonato, dibm = diisobutirilmetano) e fenilsilano como redutor, o que impacta em uma reação de baixo custo e que não necessita de exclusão de umidade ou oxigênio.

Em 2015, durante a aplicação desse protocolo em um composto nitroaromático, foi observada a formação de um subproduto com a formação de uma ligação $\mathrm{C}-\mathrm{N}$, uma anilina alquilada. Ao investigar essa reação inesperada, foi observado que o grupo nitro estaria sendo reduzido para uma espécie nitrosoareno 124 e, após acoplamento com o radical derivado da olefina 122, formaria a ligação C-N. Uma etapa adicional de redução com zinco metálico e solução de $\mathrm{HCl}_{(\mathrm{aq})}$ foi realizada no mesmo frasco reacional para otimizar o rendimento (Esquema 20). ${ }^{58}$

Essa metodologia se mostrou compatível com diversos grupos funcionais, incluindo triflatos e iodetos de arila, tioéteres, álcoois,

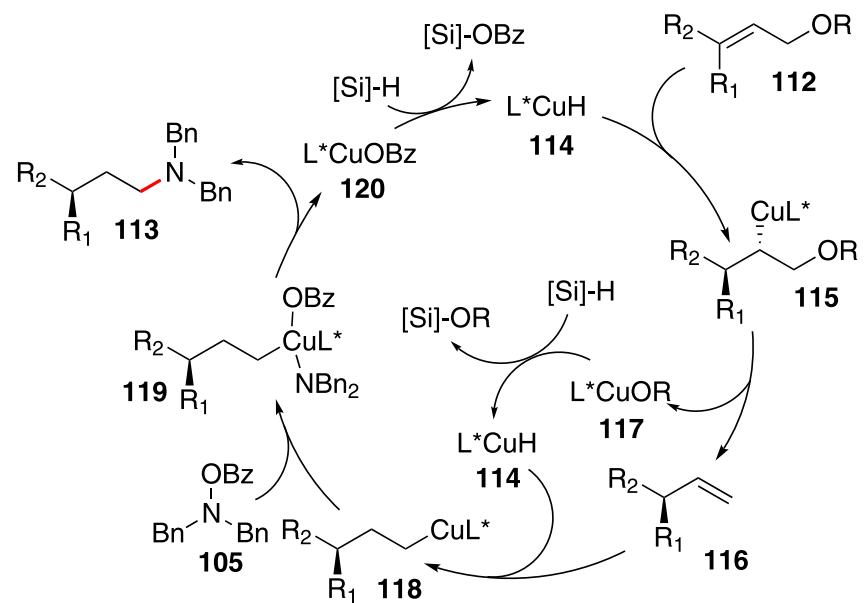

Esquema 19. Proposta mecanística para hidroaminação redutiva de transferência

aminas e cetonas, porém apresentou incompatibilidade com substratos contendo fenóis e tiofenóis.

Um dos substratos estudados (composto 125) se destaca pelo fato de ser um intermediário na síntese de um inibidor de transcriptase reversa HIV-1, e a metodologia estudada permite a transformação de 125 em 126 em apenas uma etapa, em rendimento comparável ao método convencional, que utiliza três etapas e reagentes mais caros, incluindo o cloreto de propargila 127, que também é sensível à umidade (Esquema 21). Outro exemplo é a preparação do fragmento 130, em menos etapas e tempo, em rendimento similar à rota convencional (Esquema 21).

O mecanismo proposto para essa hidroaminação ainda não está totalmente esclarecido, Baran e colaboradores propuseram a combinação de uma espécie nitrosoareno com um radical, derivados do composto nitroaromático e da olefina, respectivamente. Dois subprodutos foram identificados, uma hidroxilamina $\mathrm{N}$-alquilada e uma hidroxilamina $\mathrm{N}, \mathrm{O}$-alquilada, assim a etapa 


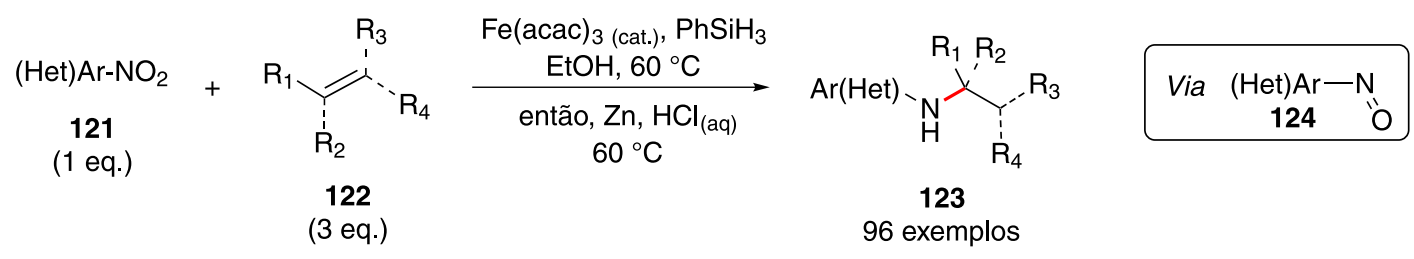

Esquema 20. Acoplamento entre nitroaromáticos e olefinas

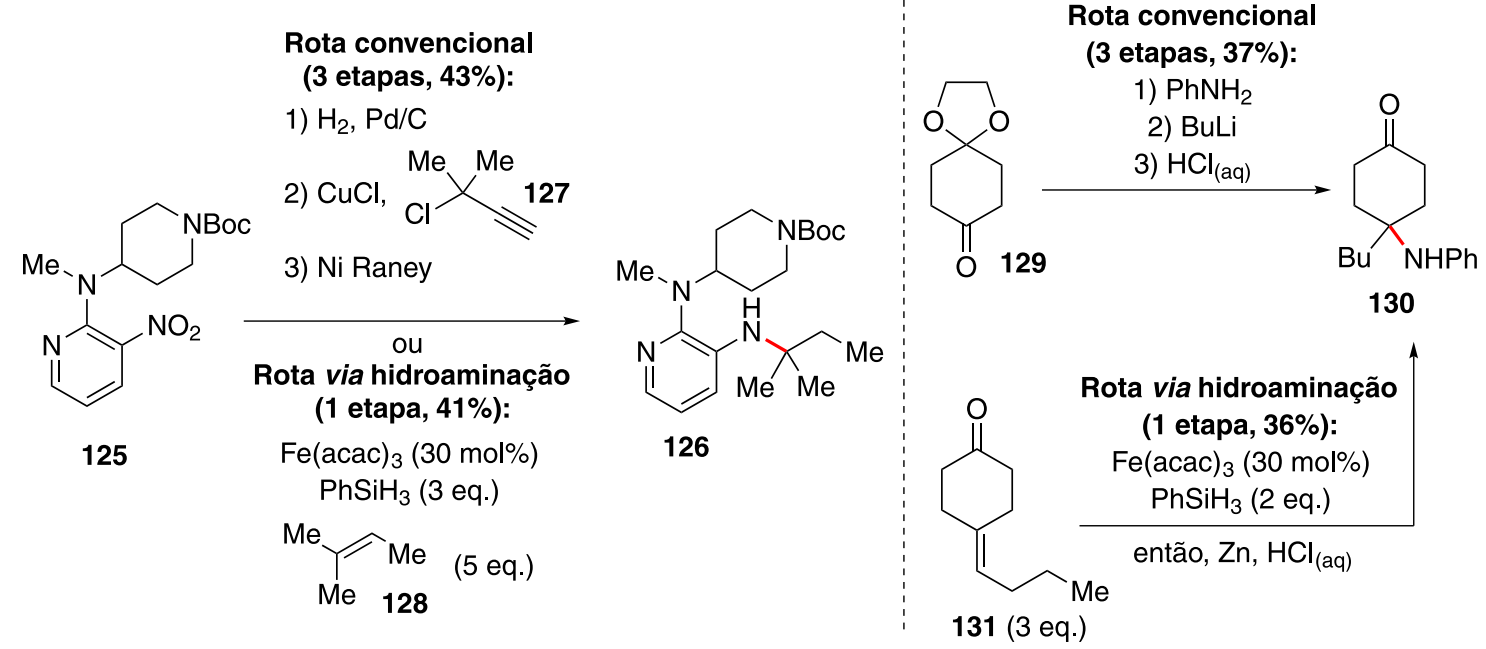

Esquema 21. Síntese dos compostos 126 e 130: rota convencional e hidroaminação

de redução desses intermediários forneceria a anilina substituída desejada.

Em 2016, Zhu, Shaver e Thomas ${ }^{59,60}$ relataram o uso do catalisador amino-bis(fenolato) de ferro (III) (132) para realizar a hidroaminação formal investigada por Baran. Esse catalisador (Figura 2) foi empregado com sucesso em reações de hidrosililação ${ }^{61}$ e polimerização radicalar. ${ }^{62}$ A carga catalítica pôde ser reduzida de $30 \mathrm{~mol} \%$ de $\mathrm{Fe}(\mathrm{acac})_{3}$ para apenas $2 \mathrm{~mol} \%$ de 132, e a temperatura reacional reduzida de $60{ }^{\circ} \mathrm{C}$ para temperatura ambiente, mantendo rendimentos similares, mostrando a vantagem com a troca da espécie de ferro (III).

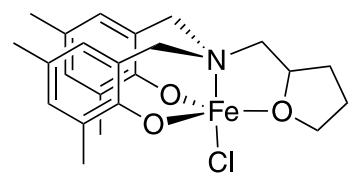

132

Figura 2. Catalisador amino-bis(fenolato) de ferro (III) (132)

\section{Hidroaminação sem metais de transição}

Processos sintéticos que evitam o uso de metais de transição são desejados na indústria farmacêutica, em que mesmo concentrações baixas de metais devem ser evitadas no produto final. Assim, a ausência de metais de transição na metodologia escolhida pode impactar em um menor custo de purificação do material.

No caso de organocatalisadores, ${ }^{63}$ como ácidos fosfóricos, tiouréias, esquaramidas ou derivados de prolina, usualmente não há problemas com umidade ou oxigênio durante sua manipulação, característica que usualmente não é encontrada em diversos métodos baseados em metais de transição.

\section{Catálise por ligação de hidrogênio}

Hidroaminações tipo Cope foram aceleradas com uso de solventes próticos,${ }^{64}$ e estudos computacionais identificaram ligações de hidrogênio que estabilizariam o estado de transição polar dessa reação. ${ }^{65}$
Dessa forma, Jacobsen e colaboradores avaliaram o uso de uma tiouréia simples como doadora de ligação de hidrogênio aplicando a teoria do funcional da densidade (DFT - density functional theory). Os autores observaram com uso da tiouréia, uma energia de ativação para a etapa de ciclização concertada $3,1 \mathrm{kcal} \mathrm{mol}^{-1}$ menor do que para a reação sem a tiouréia, indicando que tal espécie poderia ser utilizada como um catalisador desta reação (Figura 3). ${ }^{66}$

Em um trabalho prévio de Uyeda e Jacobsen, foi identificado um efeito combinado de ligação de hidrogênio e estabilização secundária do estado de transição dipolar em rearranjos enantiosseletivos de Claisen. ${ }^{67}$

Assim, diversas tiouréias contendo anéis aromáticos ricos eletronicamente (que poderiam estabilizar a carga parcial positiva desenvolvida no nitrogênio durante a ciclização) foram avaliadas para a hidroaminação de Cope. Dentre os catalisadores avaliados, o melhor resultado foi obtido com a tioureia 142, que contém um substituinte diarilpirrol. Esse catalisador foi avaliado para hidroaminação intramolecular do composto 141, fornecendo a pirrolidina $143 \mathrm{em}$ $83 \%$ de rendimento e elevado excesso enantiomérico (Esquema 22).

$\mathrm{O}$ uso de substituintes $p$ - $\mathrm{Me}, p-\mathrm{Cl}, m-\mathrm{Cl}, o-\mathrm{Cl}$ e $p$ - $\mathrm{MeO}$ no anel aromático de 141 não influenciaram significativamente na alteração do rendimento e excesso enantiomérico dos produtos ciclizados.

\section{Catálise por ácido de Brønsted}

Outra frente explorada para reações de hidroaminação sem uso de metais de transição faz uso de ácidos de Brønsted. Em 2002, Schlummer e Hartwig relataram o uso de ácidos para a ciclização de aminoalcenos contendo o nitrogênio ligado a um grupo tosila,$^{68} \mathrm{e}$ identificaram que os ácidos sulfúrico e tríflico seriam suficientemente fortes para catalisar a reação. Um possível mecanismo passaria pela protonação do alceno 144, na sequência, o carbocátion 146 seria atacado pelo nitrogênio de forma intramolecular e após perda do próton, seria formada a pirrolidina 148 (Esquema 23). O uso de aminas protegidas na forma de carbamatos ou aminas livres com os ácidos tríflico ou sulfúrico não levaram ao produto de hidroaminação. 


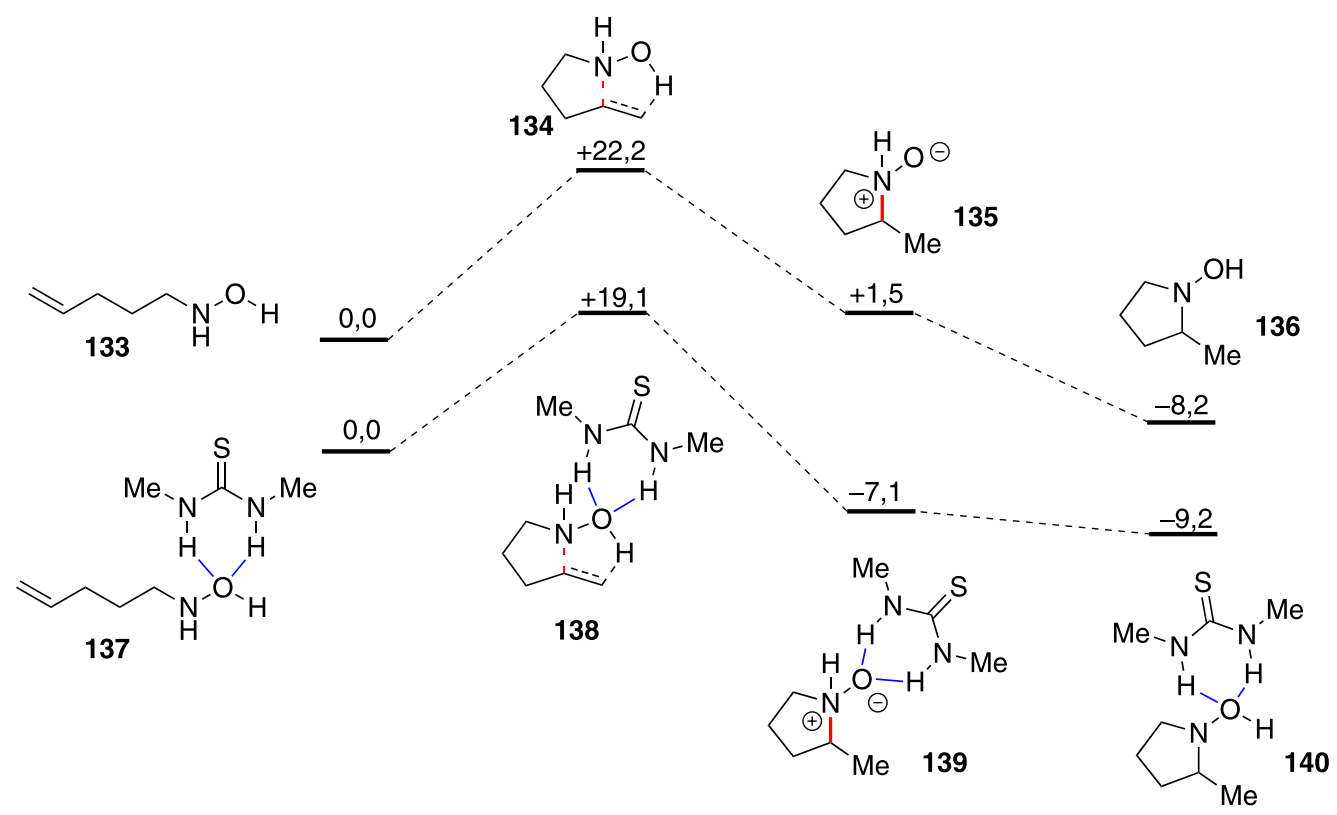

Figura 3. Energias calculadas para estruturas otimizadas da reação de hidroaminação de Cope, método B3LYP/6-311+G(d,p), energias em kcal.mol ${ }^{-1}$. Ligações de hidrogênio estão destacadas em azul

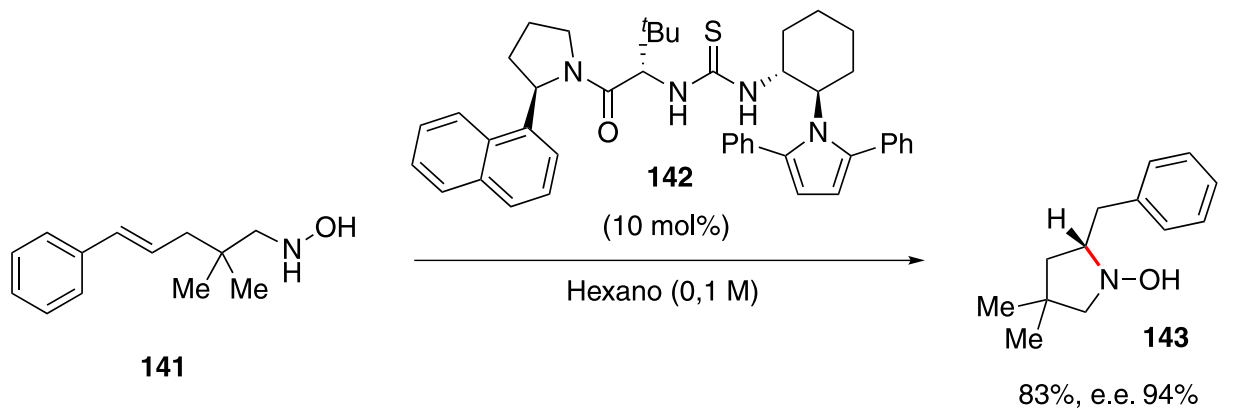

Esquema 22. Hidroaminação tipo Cope catalisada pela tiouréia 142
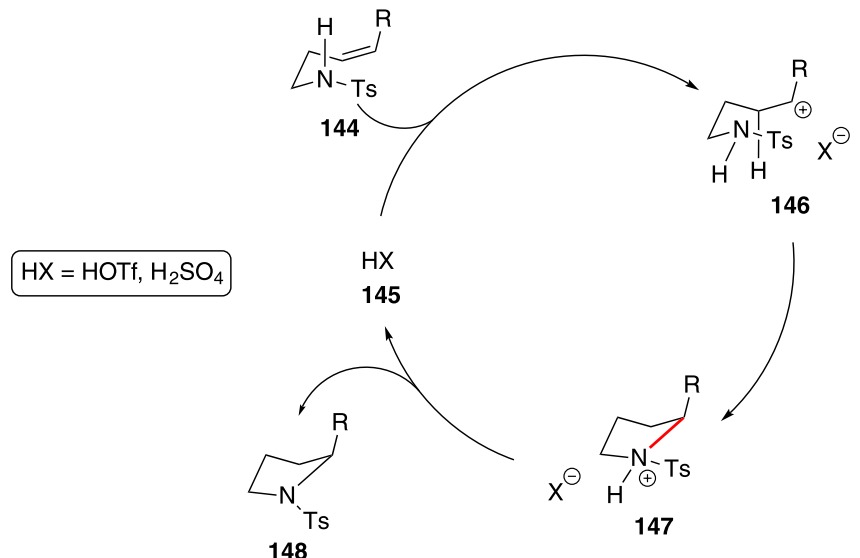

Esquema 23. Ciclização de aminoalcenos catalisada por ácido de Brønsted

Em 2008, Ackermann e Althammer relataram o uso de ácidos fosfóricos para formação de pirrolidinas via hidroaminação, porém, o uso do catalisador enantiopuro levou à baixa discriminação das faces do carbocátion intermediário, levando ao produto com 17\% de excesso enantiomérico. ${ }^{69}$ Apesar de diversos ácidos de Brønsted terem sido estudados, as principais reações altamente enantiosseletivas que os utilizam envolvem ativação de uma ligação carbono-heteroátomo ou heteroátomo-heteroátomo, usualmente uma carbonila ou imina..$^{70,71}$
A protonação de uma carbonila ou imina gera uma espécie que pode fazer uma ligação de hidrogênio com a base conjugada do ácido de Brønsted enantiopuro, mantendo a informação quiral próxima ao centro eletrofílico reativo e auxiliando na organização molecular que favorece um dos estados de transição diastereoisoméricos. Por outro lado, a protonação de um alceno leva a um carbocátion, apesar da base conjugada quiral poder se manter próxima por interações eletrostáticas, a rigidez dessa interação é consideravelmente menor do que no caso anterior, resultando em uma baixa discriminação das faces enantiotópicas.

Para atacar esse desafio, Toste e colaboradores reportaram uma estratégia, em 2011, baseada no uso de dienos e ácidos ditiofosfóricos. $^{72}$ Esses ácidos de Brønsted seriam fortes o suficiente para protonar o dieno e a base conjugada seria nucleofílica, podendo formar uma ligação C-S. Em seguida, o nitrogênio poderia realizar uma reação $\mathrm{S}_{\mathrm{N}} 2$ ' enantiosseletiva, formando a pirrolidina enantioenriquecida e liberando a base quiral. Um exemplo dessa reação é mostrado a seguir no Esquema 24.

\section{Construção de alcaloides indolizidínicos}

A classe de alcaloides indolizidínicos ([4.3.0]-1-azabiciclos) possui grande diversidade e complexidade estrutural, ${ }^{73}$ atraindo a atenção de diversos químicos sintéticos. Assim, uma estratégia envolvendo bis-hidroaminação simplificaria consideravelmente o desafio sintético. Em vista disso, e da dificuldade de obter tal transformação 


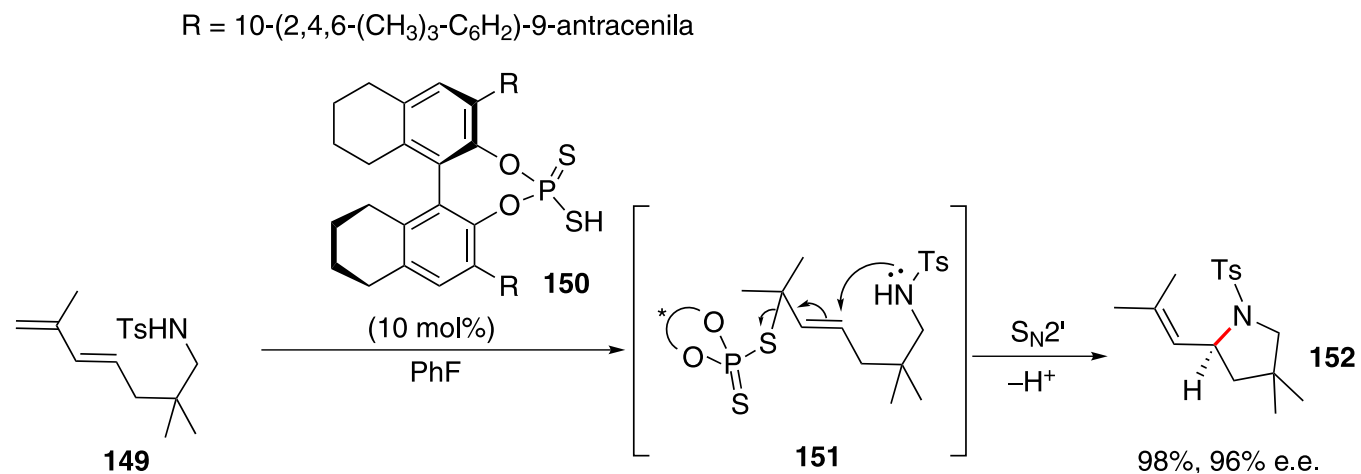

Esquema 24. Hidroaminação intramolecular catalisada por ácido ditiofosfórico

com métodos conhecidos até então, Shenvi e colaboradores estudaram um protocolo de bis-hidroaminação formal. ${ }^{74,75}$

A reação a partir da amina 153 envolve o uso de $\mathrm{BH}_{3} \cdot \mathrm{DMS}$ e iodo molecular para realizar a hidroboração regiosseletiva das duplas trissubstituídas, gerando o intermediário 156. Para essa primeira etapa, foi observada ser essencial a adição lenta de iodo sob exclusão de luz, evitando assim a quebra da ligação potencialmente fotolábil B-I. Com a adição de $\mathrm{NaOMe}$ e uma segunda porção de $\mathrm{I}_{2}$ foi possível promover uma migração, formando o intermediário pirrolidina $\mathbf{1 5 8}$, e após tratamento oxidativo o álcool foi instalado, fornecendo o composto 159. Para a formação do segundo ciclo, um protocolo baseado na reação de Mitsunobu foi utilizado (Esquema 25). ${ }^{76}$

Os estados de transição 154 e $\mathbf{1 5 5}$, contendo ciclos de seis membros na geometria de bote, foram propostos com base na estereoquímica observada no produto final majoritário.

Essa estratégia foi aplicada na síntese formal da lepadiformina (166) por Tabor e Shenvi (Esquema 26).$^{75}$ Esse alcaloide de origem marinha apresenta uma estrutura tricíclica congestionada, o que torna um desafio o uso da metodologia apresentada.

Assim, a partir do dieno $\mathbf{1 6 1},{ }^{77}$ foi realizado o protocolo de hidroaminação para formação do biciclo $163,{ }^{78}$ e o último ciclo presente no produto natural foi forjado através de uma reação nas

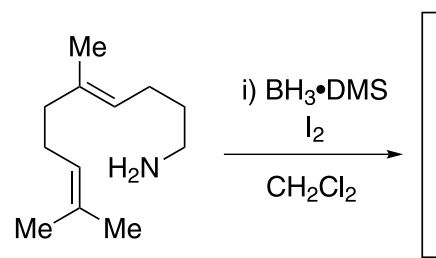

153

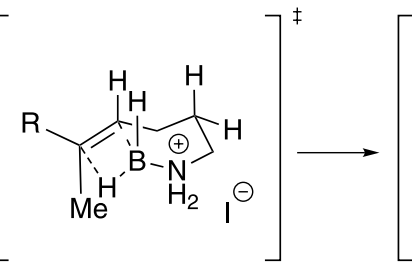

154

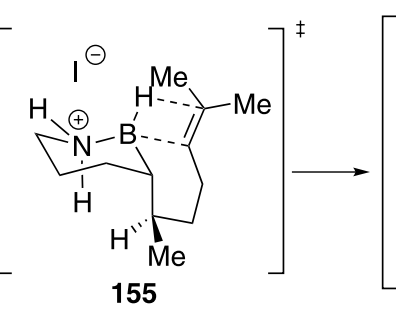

155

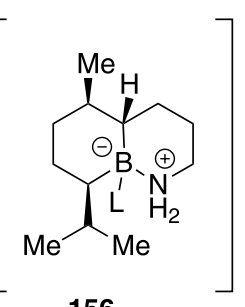

156 então, $\mathrm{I}_{2}$

$\mathrm{NaOMe}$

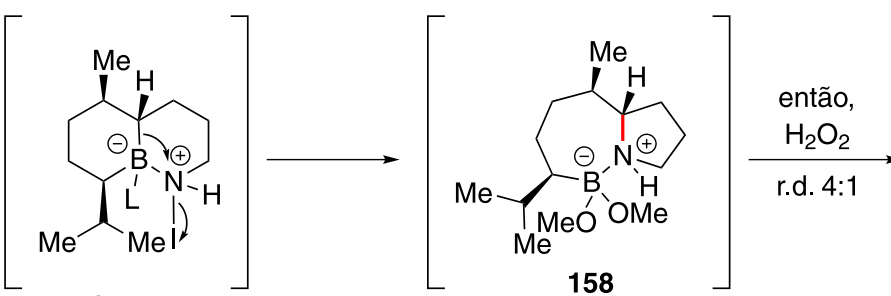

157<smiles>CC(C)C(O)CCC(C(C)C)[C@H]1CCCN1</smiles>

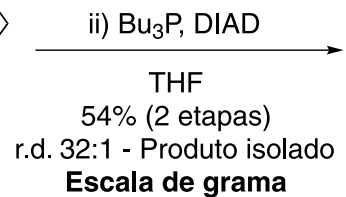

Escala de grama<smiles></smiles>

Esquema 25. Formação da indolizina 160 via hidroaminação formal<smiles>C/C=C\CCC1=C(CCCN)CCCC1</smiles>

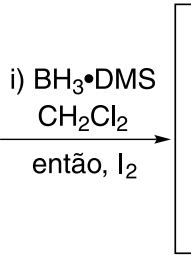

iii) $m$ CPBA

$\mathrm{CH}_{2} \mathrm{Cl}_{2}$

iv) TFAA, KCN

(81\%, 2 etapas)

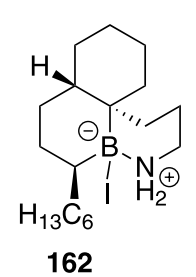

162

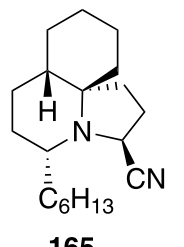

165

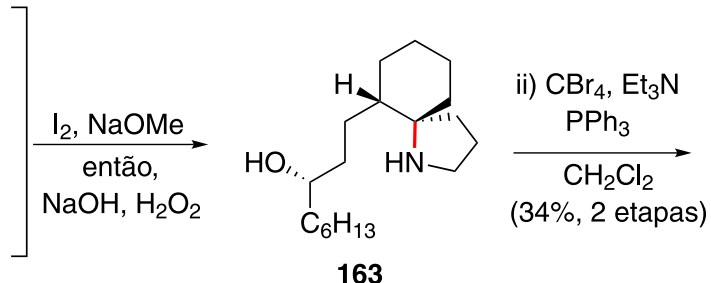

Ref. 79: v) $\mathrm{H}_{2} \mathrm{SO}_{4}, \mathrm{MeOH} 43 \%$

vi) $\mathrm{LAH} 94 \%$

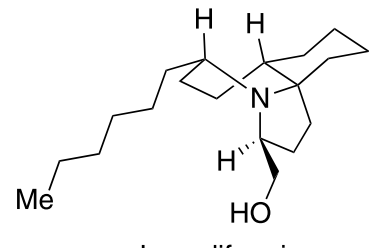

Lepadiformina 
condições de Appel. A síntese do intermediário 165 empregou uma $\alpha$-cianação oxidativa, relatada anteriormente por Rychnovsky e colaboradores, ${ }^{79}$ que também conduziram a conclusão da síntese de 166, por meio da metanólise do grupo nitrila e redução completa com $\mathrm{LiAlH}_{4}$ (Esquema 26).

\section{CONCLUSÕES E PERSPECTIVAS}

As reações de hidroaminação passaram por grandes avanços e contam com métodos que permitem diferentes regiosseletividades e estratégias enantiosseletivas. Métodos de hidroaminações formais que permitem a utilização de metais mais baratos como cobre e ferro estão sendo desenvolvidos com sucesso, tornando a síntese mais atrativa economicamente. $\mathrm{O}$ uso de métodos livre de metais de transição também é notável, utilizando conceitos estabelecidos, como ativação por ligação de hidrogênio e uso de ácidos de Brønsted.

Um dos grandes desafios ainda se encontra no uso direto de amônia nesse tipo de reação, um importante passo para esse desenvolvimento foi o uso de catálise de $\mathrm{Au}$ (I) relatado por Bertrand e colaboradores. ${ }^{16}$ No entanto, usualmente essa tarefa tem sido atacada de modo indireto, por exemplo, pelo uso de $\mathrm{Ph}_{2} \mathrm{C}=\mathrm{NH}$ com catálise de ródio ${ }^{31}$ e $\mathrm{Bn}_{2} \mathrm{NOBz}$ com catálise de cobre, ${ }^{51,53,54}$ os quais podem levar ao produto formal de uma hidroaminação com amônia após uma etapa extra, hidrólise da imina ou hidrogenação da dibenzilamina, respectivamente.

Outro desafio que vem sendo discutido é a necessidade de evitar o uso de um dos parceiros (amina ou composto insaturado) em excesso para reações intermoleculares, pois isso impactaria em uma perda da economia atômica, que é uma das grandes vantagens de utilizar reações de hidroaminação.

Diversos mecanismos têm sido propostos para essa classe de reações, porém, há falta de estudos mecanísticos detalhados, o que pode impactar na dificuldade de propor novos sistemas catalíticos de modo racional. Nesse contexto, a utilização de métodos computacionais pode auxiliar na compreensão e previsão de ação dos catalisadores.

\section{AGRADECIMENTOS}

Os autores agradecem o apoio financeiro da Fundação de Amparo à Pesquisa do Estado de São Paulo (FAPESP, processos $n^{\circ}$ 2014/26378-2, 2014/25770-6, 2015/08199-6), da CAPES e do CNPq. Os autores agradecem a revisão do texto realizada pela Dra. Carolina M. A. Sant'Ana e M. ${ }^{\text {a }}$ Mariana C. Frojuello.

\section{REFERENCIAS}

1. Sorribes, I.; Junge, K.; Beller, M.; J. Am. Chem. Soc. 2014, 136, 14314.

2. Ju, Y.; Varma, R. S.; J. Org. Chem. 2006, 71, 135.

3. Horn, M.; Mayr, H.; Lacôte, E.; Merling, E.; Deaner, J.; Wells, S.; McFadden, T.; Curran, D. P.; Org. Lett. 2012, 14, 82.

4. Dangerfield, E. M.; Plunkett, C. H.; Win-Mason, A. L.; Stocker, B. L.; Timmer, M. S. M.; J. Org. Chem. 2010, 75, 5470.

5. Sheehan, J. C.; Hess, G. P.; J. Am. Chem. Soc. 1955, 77, 1067.

6. El Dine, T. M.; Erb, W.; Berhault, Y.; Roude, J.; Blanchet, J.; J. Org. Chem. 2015, 80, 4532.

7. Surry, D. S.; Buchwald, S. L.; Angew. Chem., Int. Ed. 2008, 47, 6338.

8. Hartwig, J. F.; Acc. Chem. Res. 2008, 41, 1534

9. Para revisão sobre hidroaminação catalisada por metais de transição tardios, ver: Huang, L.; Arndt, M.; Gooßen, K.; Heydt, H.; Gooßen, L. J.; Chem. Rev. 2015, 115, 2596.

10. Para revisão sobre hidroaminação de alcenos, ver: Bernoud, E.; Lepori, C.; Mellah, M.; Schulz, E.; Hannedouche, J.; Catal. Sci. Technol. 2015, $5,2017$.
11. Anastas, P. T.; Warner, J. C.; Green Chemistry: Theory and Practice, Oxford University Press: New York, 1998

12. Johns, A. M.; Sakai, N.; Ridder, A.; Hartwig, J. F.; J. Am. Chem. Soc. 2006, 128, 9306.

13. Os 12 princípios de química verde estão detalhados na referência 11 .

14. Shen, Q.; Hartwig, J. F.; J. Am. Chem. Soc. 2006, 128, 10028.

15. Surry, D. S.; Buchwald, S. L.; J. Am. Chem. Soc. 2007, 129, 10354.

16. Lavallo, V.; Frey, G. D.; Donnadieu, B.; Soleihavoup, M.; Bertrand, G.; Angew. Chem. Int. Ed. 2008, 47, 5224.

17. Mizushima, E.; Hayashi, T.; Tanaka, M.; Org. Lett. 2003, 5, 3349.

18. Howk, B. W.; Little, E. L.; Whitman, G. M.; J. Am. Chem. Soc. 1954, $76,1899$.

19. Pohlki, F.; Doye, S.; Angew. Chem., Int. Ed. 2001, 40, 2305.

20. Straub, B. F.; Bergman, R. G.; Angew. Chem., Int. Ed. 2001, 40, 4768.

21. Tobisch, S.; Chem. Eur. J. 2007, 13, 4884.

22. Mujahidin, D.; Doye, S.; Eur. J. Org. Chem. 2005, 2005, 2689.

23. Composto 27 foi sintetizado em um total de 7 etapas a partir de reagentes comerciais.

24. Manna, K.; Xu, S.; Sadow, A. D.; Angew. Chem., Int. Ed. 2011, 50, 1865 .

25. Nagano, T.; Kobayashi, S.; J. Am. Chem. Soc. 2008, 131, 4200.

26. Anderson, C. E.; Overman, L. E.; J. Am. Chem. Soc. 2003, 125, 12412.

27. Pattillo, C. C.; Strambeanu, I. I.; Calleja, P.; Vermeulen, N. A.; Mizuno, T.; White, M. C.; J. Am. Chem. Soc. 2016, 138, 1265.

28. Ngai, M.-Y.; Barchuk, A.; Krische, M. J.; J. Am. Chem. Soc. 2007, 129, 12644.

29. Patil, N. T.; Wu, H.; Kadota, I.; Yamamoto, Y.; J. Org. Chem. 2004, 69, 8745 .

30. Qiu, S.; Wei, Y.; Liu, G.; Chem. Eur. J. 2009, 15, 2751.

31. Xu, K.; Wang, Y.-H.; Khakyzadeh, V.; Breit, B.; Chem. Sci. 2016, 7, 3313

32. Stork, G.; Landesman, H. K.; J. Am. Chem. Soc. 1956, 78, 5128.

33. Mukherjee, S.; Yang, J. W.; Hoffmann, S.; List, B.; Chem. Rev. 2007, 107,5471 .

34. Uchimaru, Y.; Chem. Commun. 1999, 1133.

35. Sakai, K.; Kochi, T.; Kakiuchi, F.; Org. Lett. 2011, 13, 3928.

36. Wakatsuki, Y.; J. Organomet. Chem. 2004, 689, 4092.

37. Siengalewicz, P.; Rinner, U.; Mulzer, J.; Chem. Soc. Rev. 2008, 37, 2676.

38. Kahsai, A. W.; Zhu, S.; Wardrop, D. J.; Lane, W. S.; Fenteany, G.; Chem. Biol. 2006, 13, 973 .

39. Takahashi, K.; Tomita, F.; J. Antibiot. 1983, 36, 468.

40. Chiba, H.; Oishi, S.; Fujii, N.; Ohno, H.; Angew. Chem., Int. Ed. 2012, 51,9169

41. Composto $\mathbf{8 4}$ foi sintetizado em um total de 23 etapas a partir de reagentes comerciais.

42. Allan, K. M.; Stoltz, B. M.; J. Am. Chem. Soc. 2008, 130, 17270.

43. Prier, C. K.; Rankic, D. A.; MacMillan, D. W. C.; Chem. Rev. 2013, 113, 5322.

44. Musacchio, A. J.; Nguyen, L. Q.; Beard, G. H.; Knowles, R. R.; J. Am. Chem. Soc. 2014, 136, 12217.

45. Crabtree, R. H.; Davis, M. W.; J. Org. Chem. 1986, 51, 2655.

46. Para uma revisão sobre grupos diretores, ver: Rousseau, G.; Breit, B.; Angew. Chem., Int. Ed. 2011, 50, 2450.

47. Kawasaki, Y.; Ishikawa, Y.; Igawa, K.; Tomooka, K.; J. Am. Chem. Soc. 2011, 133, 20712.

48. Smith, S. M.; Takacs, J. M.; J. Am. Chem. Soc. 2010, 132, 1740

49. Murphy, S. K.; Bruch, A.; Dong, V. M.; Angew.Chem., Int. Ed. 2014, 53, 2455.

50. Lipshutz, B. H.; Frieman, B. A.; Angew. Chem., Int. Ed. 2005, 44, 6345.

51. Xi, Y.; Butcher, T. W.; Zhang, J.; Hartwig, J. F.; Angew. Chem., Int. Ed. 2016, 55, 776. 
52. A estereoquímica relativa foi determinada após conversão de $\mathbf{1 0 9}$ no cloridrato de 3-aminociclopentanol e comparação dos dados de RMN de ${ }^{1} \mathrm{H}$ com amostras autênticas dos isômeros cis e trans.

53. Zhu, S.; Buchwald, S. L.; J. Am. Chem. Soc. 2014, 136, 15913.

54. Zhu, S.; Niljianskul, N.; Buchwald, S. L.; Nat. Chem. 2016, 8, 144.

55. Shi, S.-L.; Buchwald, S. L.; Nat. Chem. 2015, 7, 38.

56. Lo, J. C.; Yabe, Y.; Baran, P. S.; J. Am. Chem. Soc. 2014, 136, 1304.

57. Lo, J. C.; Gui, J.; Yabe, Y.; Pan, C.-M.; Baran, P. S.; Nature 2014, 516, 343.

58. Gui, J.; Pan, C.-M.; Jin, Y.; Qin, T.; Lo, J. C.; Lee, B. J.; Spergel, S. H.; Mertzman, M. E.; Pitts, W. J.; La Cruz, T. E.; Schmidt, M. A.; Darvatkar, N.; Natarajan, S. R.; Baran, P. S.; Science 2015, 348, 886.

59. Zhu, K.; Shaver, M. P.; Tomas, S. P.; Chem. Asian J. 2016, 11, 977.

60. Zhu, K.; Shaver, M. P.; Tomas, S. P.; Chem. Sci. 2016, 7, 3031.

61. Zhu, K.; Shaver, M. P.; Tomas, S. P.; Eur. J. Org. Chem. 2015, 2015, 2119.

62. Schroeder, H.; Lake, B. R. M.; Demeshko, S.; Shaver, M. P.; Buback, M.; Macromolecules 2015, 48, 4329.

63. Para revisões sobre organocatálise, ver edição especial: Chem. Rev. 2007, 107

64. Moran, J.; Gorelsky, S. I.; Dimitrijevic, E.; Lebrun, M.-E.; Bédard, A.-C.; Séguin, C.; Beauchemin, A. M.; J. Am. Chem. Soc. 2008, 130, 17893.
65. Acevedo, O.; Jorgensen, W. L.; J. Am. Chem. Soc. 2006, 128, 6141.

66. Brown, A. R.; Uyeda, C.; Brotherton, C. A.; Jacobsen, E. N.; J. Am. Chem. Soc. 2013, 135, 6747.

67. Uyeda, C.; Jacobsen, E. N.; J. Am. Chem. Soc. 2011, 133, 5062.

68. Schlummer, B.; Hartwig, J. F.; Org. Lett. 2002, 4, 1471.

69. Ackermann, L.; Althammer, A.; Synlett 2008, 995.

70. Hatano, M.; Maki, T.; Moriyama, K.; Arinobe, M.; Ishihara, K.; J. Am. Chem. Soc. 2008, 130, 16858.

71. Sai, M.; Yamamoto, H.; J. Am. Chem. Soc. 2015, 137, 7091.

72. Shapiro, N. D.; Rauniyar, V.; Hamilton, G. L.; Wu, J.; Toste, F. D.; Nature 2011, 470, 245.

73. Michael, J. P.; Nat. Prod. Rep. 2008, 25, 139.

74. Pronin, S. V.; Tabor, M. G.; Jansen, D. J.; Shenvi, R. A.; J. Am. Chem. Soc. 2012, 134, 2012.

75. Tabor, M. G.; Shenvi, R. A.; Org. Lett. 2015, 17, 5776.

76. A estereoquímica relativa de $\mathbf{1 6 0}$ foi determinada a partir da estrutura de raio- $\mathrm{X}$ do respectivo cloridrato.

77. Composto $\mathbf{1 6 1}$ foi sintetizado em um total de 6 etapas a partir de reagentes comerciais.

78. A estereoquímica relativa de $\mathbf{1 6 3}$ foi confirmada a partir de análise de raio-X do respectivo derivado 3,5-dinitrobenzoato-3,5-dinitrobenzamida.

79. Perry, M. A.; Morin, M. D.; Slafer, B. W.; Rychnovsky, S. D.; J. Org. Chem. 2012, 77, 3390. 